\title{
A Multi-Criteria Approach for FMEA in Product Development in Industry 4.0
}

José M. M. de ANDRADE, Athon F. C. S. de M. LEITE, Matheus B. CANCIGLIERI, Anderson L. SZEJKA ${ }^{1}$, Eduardo de F. R. LOURES and Osiris CANCIGLIERI Junior Industrial and Systems Engineering Graduate Program, Pontifical Catholic University of Paraná, Curitiba - Paraná, Brazil

\begin{abstract}
In Industry 4.0, current trends on data analysis and real-time processing are intertwined with the use of development tools while conceiving products. The quality of information plays a pivotal role in this process, as the heterogeneity of unprocessed data may result in issues that increase the product's cost and development time. In this context, the Failure Mode \& Effect Analysis (FMEA) is a tool that aids decision-making by presenting pre-processed useful data that can improve product design, maintainability and manufacturing. FMEA criteria, although standardised, has ramifications that have different impacts and weight in an organisation, which might end up resulting in subjective evaluations. To cope with this issue and improve the quality of the information in product development, this research proposes a Multi-Criteria approach to define the importance of FMEA criteria and their impacts in organisations in a real industrial scenario. This research is applied using a case on a Brazilian electronics manufacturer, using AHP and TOPSIS Multi-Criteria Decision Making (MCDM) methods. Findings show that by traditional methods different evaluators end up generating different data and weights on FMEA, resulting in different results. In this sense, the application of the MultiCriteria methods ends up ranking the importance of criteria and evaluating the inputs from all departments, returning more precise information. Furthermore, the weighting scale of FMEA has been shifted to a customised scale for the organisation in the study, based on AHP, more suitable to their needs and following their perception, to support the decision-makers most assertively.
\end{abstract}

Keywords. Industry 4.0, FMEA, Multiple Criteria Decision Making, AHP, TOPSIS.

\section{Introduction}

In the era of Industry 4.0 transformation, sensors, machines, workpieces, and IT systems are connected to improve the value offered while optimizing resources and decreasing development time. To apply such technologies, enterprises rely significantly on the quality of data to improve their decision-making process. This data has to be gathered and analysed, but the focus usually is on the analysis stage while the gathering and preprocessing are neglected often and might contain imprecise information due to: poor gathering process, the bias of collector or highly dynamic environments [1] [2] [3].

Currently, Product Development has increased the number of information necessary to improve its overall delivery quality and product's longevity in the market [4]. In this context, tools such as the Failure Mode \& Effect Analysis (FMEA) offer ways of keeping development cycles active for longer and increasing focus on continuous improvement on products [5]. Despite its benefits to Product Development, the process of FMEA still 
relies heavily on the evaluators' opinion and might be affected by their position/function in an organisation, which might result in biased information that could be imprecise for sharing in an Industry 4.0 scenario [6].

This research has its focus on reducing bias on data gathering and analysis by offering a different approach that adds a Multi-Criteria Decision-Making (MCDM) approach to FMEA, to improve decision-making in a company, and, therefore, improving the quality of the information in a transdisciplinary environment such as the Product Development in Industry 4.0. The domains that are being approached in this research are depicted in Figure 1.

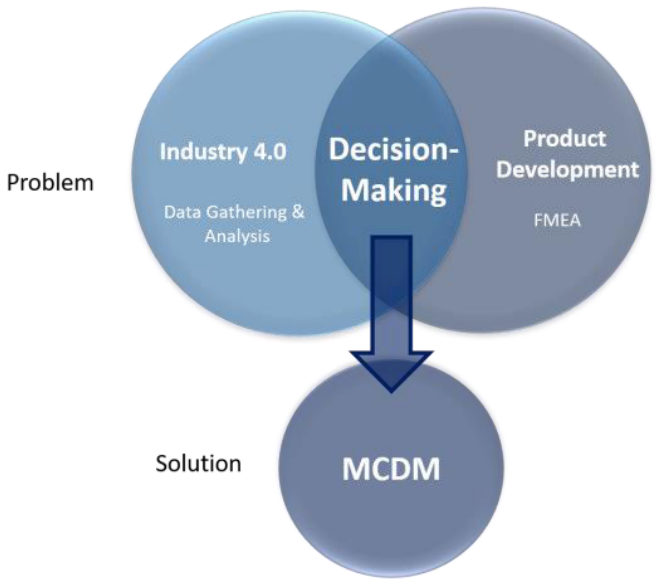

Figure 1. Domains of the Research.

As depicted in Figure 1, the "Problem" field of this research approaches the domain of Industry 4.0, more specifically the issues in its data gathering and analysis, and the issues of the FMEA tool in the Product Development domain. Both are related to the final quality of the Decision-Making Process. In another aspect, the "Solution" field of this research approaches the domain of MCDM, as ways of improving the quality of Decision-Making by reducing the bias of deciders.

\section{Materials and Methods}

This research main focus is to propose a multicriteria approach to define the failure modes importance of FMEA in an industrial scenario. To achieve this goal this research is considered to be of an applied nature, whilst its approach is considered qualitative. Finally, the technical procedures adopted to achieve the research objectives were a literature review on the conceptual background alongside an experimental case based on MCDM techniques.

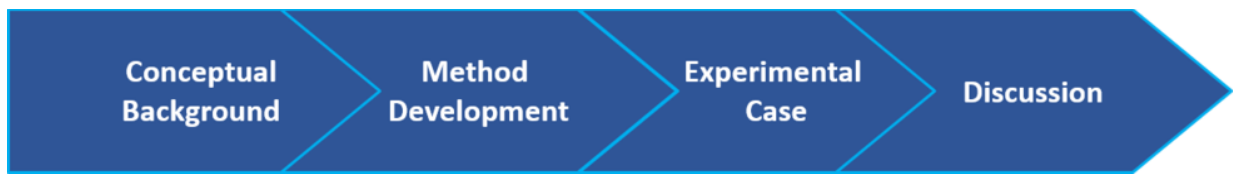

Figure 2. Methodological Procedures.

The approach will be developed using MCDM algorithms to develop a different approach to FMEA with more consistent information and more accurate prioritisation. 
The study will be validated through an experimental case, in which a FMEA application of a Switched-Mode Power Supply from a Brazilian electronics manufacturer will be scrutinized and compared considering the results before and after the application of the approach with MCDM.

\section{Conceptual Background}

\subsection{Industry 4.0 and Data Gathering \& Analysis}

The current convergence and integration of new technologies in the field of manufacturing is being called "Industry 4.0" and refers to the Fourth Industrial Revolution, presenting remarkable differences concerning previous revolutions, which originally occurred within the factories and then left to be adopted by society, to a more holistic and integrated vision [7][8][9][10]. The basis of this vision relies significantly on data, which is generated in large volume, by various devices in industrial, commercial and residential environments.

Data is a valuable asset in the process of Decision-Making. In their "raw" form, through mining algorithms and other methodologies, they are processed to improve their quality, usability, accessibility and portability [11]. Once transformed, data is key to more agile and assertive decisions, a remarkable feature that denotes the ability to analyse and implement real-time changes required by the Fourth Industrial Revolution [8][12]. In this context, this new scenario requires higher quality and reliability of the information, where data is evaluated according to integrity, consistency, credibility, accuracy and clarity in its parameters, so that any analysis can discover models and patterns, relevant characteristics or trends in organisational historical records, the "Log of events" [13].

In another aspect, the original data collected are not properly analysed in early stages of decision-making, as they present bias, inaccuracy, redundancy, ambiguity, irrelevance, lack of pattern, manual collection, with heterogeneous interpretations, different meanings, use of personal language in its creation, and transcription failures [4][14]. Thus, its analysis is limited, having restricted interpretation, difficult understanding, and demanding excessive time for processing, hindering the extraction of knowledge and leading to inefficient solutions which compromise decision-making [4][15].

\subsection{Failure Mode Evaluation \& Analysis - FMEA}

FMEA (Failure Mode Evaluation and Analysis) is a specific systematic methodology for identifying, evaluating and preventing problems in a product, system, project, process or service, through a risk analysis that considers the possibility of failures, risks and relevant impacts [6][16]. The methodology is used at various stages of a product's life cycle and serves the development team by identifying potential modes of failure based on previous experiences, minimising the impacts of risks and development time, as well as associated costs reduction [17]. Also, FMEA is an important strategic tool to extend product longevity and serves as a direction to improve products [5].

FMEA methods use the numerical risk priority value (RPN) as the product of three factors: Occurrence (O), Severity (S) and Detection (D), defined by the RPN formula = $\mathrm{O} \times \mathrm{S} \times \mathrm{D}$, where for each variable a weight predefined by a qualitative scale is assigned [17]. The FMEA systems and projects have weights as shown in Table 1. 
Table 1. Qualitative scale for FMEA.

\begin{tabular}{cccc}
\hline $\begin{array}{c}\text { Qualitative } \\
\text { Scale }\end{array}$ & Severity (S) & Occurrence (O) & Detection (D) \\
\hline 1 & No & Almost never & Almost certain \\
\hline 2 & Very Slight & Remote & Very high \\
\hline 3 & Slight & Very Slight & High \\
\hline 4 & Minor & Slight & Moderately high \\
\hline 5 & Moderate & Low & Medium \\
\hline 6 & Significant & Medium & Low \\
\hline 7 & Major & Moderately high & Very Slight \\
\hline 8 & Extreme & High & Remote \\
\hline 9 & Serious & Very high & Almost impossible \\
\hline 10 & Hazardous & Almost certain &
\end{tabular}

It is important to state that the literature emphasizes however that these weights and criteria are not a standard and may vary according to the experience of the FMEA team, and that it should consider specific factors for each project under study and analysis [6][16]. Furthermore, the literature points out that FMEA teams must be multidisciplinary and recommends working on its application in synchronicity [5].

Regarding the results of the implementation of FMEA, the team, in possession of the information and knowledge discovered from the analysis, should develop an action plan to mitigate risks and their impacts, evaluate and measure results and promote continuous process improvement, while considering the three risk factors (Severity, Occurrence and Detection) [17][18]. Literature points, however, that consensus on results might be influenced by the background of the evaluators of the FMEA team, which can create negative effects in and Industry 4.0 scenario by reducing reliability on data [1] [5] [6].

\subsection{Multi-Criteria Decision Making Techniques}

The original data collected in early stages of decision-making are quite often poorly analysed and this might result in negative effects in products and systems [4][14]. In this context, Multi-Criteria Decision Making (MCDM) can provide better data analysis so that companies can make more agile and assertive decisions, which is key for the Fourth Industrial Revolution. MCDM can provide an improved form of classification of data, expanding the cognitive capacity of the human being in his learning process, organizing the information, recognizing patterns, facilitating the deduction and completion, detecting the expected and discovering the unexpected [19][20].

This research approaches two Multi-Criteria Decision-making techniques. The first is the Analytic Hierarchy Process (AHP), and the second is the Technique for Order Preference by Similarity to Ideal Solution (TOPSIS). Both can be combined to provide a more precise decision supporter in fields that require multiple views and considerations. The choice of those techniques is based on previous research, presenting the combination of AHP and/or TOPSIS as frequently used MCDM techniques, and their association with FMEA [5][6][19].

The AHP was developed by Thomas Saaty during the 70s and is a systematic method applied in unstructured problems with different decision-making situations, ranging from simple to complex [21][22]. AHP is divided into four main phases, being: (1) Structure the problem in hierarchical form; (2) Obtain the Judgemental matrix through pairwise comparisons; (3) Identify individual priorities and consistency of comparisons; and (4) Aggregation of the identified individual priorities. 
TOPSIS was developed by Hwang and Yoon in 1981 and is a multi-criteria decision analysis method that compares and selects alternatives based on criteria and their respective weights, normalizing their scores and calculating distances between each alternative of ideas solutions, seeking the approximation of the positive solution and the removal of the negative solution. In other words, it is a technique for evaluating the performance of alternatives through the similarity of these with an ideal solution. In TOPSIS, the best alternative is the closest to the ideal solution compared to the others [19].

The method is divided into 7 steps; (1) Performance Matrix, (2) Normalization, (3) Weighted Standard Matrix, (4) Positive and Negative Ideal Solutions, (5) Positive Ideal Solutions ( $\mathrm{Si}^{*}$ ) and Negative (Si'), (6) Similarity and (7) Ranking/Classification. Table 1 provides a summary of the TOPSIS model, bringing all the aforementioned steps and a description explaining each step and their formulae.

\section{Approach for Multi-Criteria Decision Making for FMEA}

In this research, the data from an already existent Product FMEA was used, applying the proposed MCDM approach to evaluate the impact of the selection of qualitative weights of the FMEA made by three expert evaluators of the project. The expected result was a change in the definition of priorities for the elaboration of the action plans. To improve the application of the MCDM methods chosen for FMEA, a spreadsheet tool containing AHP and TOPSIS algorithms was developed.

The product in the analysis is a switched-mode power supply, made by a Brazilian electronics manufacturer. The company uses FMEA for about six years and usually works with 3 to 6 evaluators from different departments and backgrounds on the same product (depending on the complexity of the product and time availability). In their procedure, evaluators define the failure modes in a group, filling, in sequence, the FMEA table on their own and later gathering again to compare their results to find a consensus, which demands time and may be influenced by the evaluators' background. For this application, the ten failure modes identified for the product were approached and analysed by the MCDM approach. A depiction of the approach is presented in Figure 3.

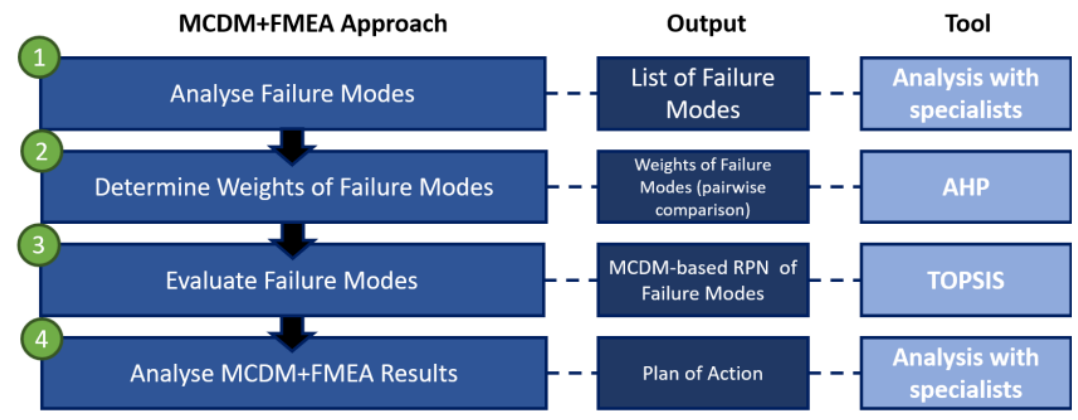

Figure 3. MCDM+FMEA approach.

The proposed MCDM approach for FMEA starts with an analysis of the failure modes of the product in study and ends by creating a plan of action to reduce the effects of failure modes. In this experimental case, both this analysis, represented by details 1 and 4 of Figure 3, were not developed, as the data input was an already existent FMEA, so both steps were already performed. 
The determination of wights for FMEA was done using the AHP technique with all the three original evaluators, based on the preparedness of the R\&D team to solve the failure mode, in terms of know-how (Detail 2 of Figure 3). The failure modes were compared using AHP, as depicted in Figure 4.

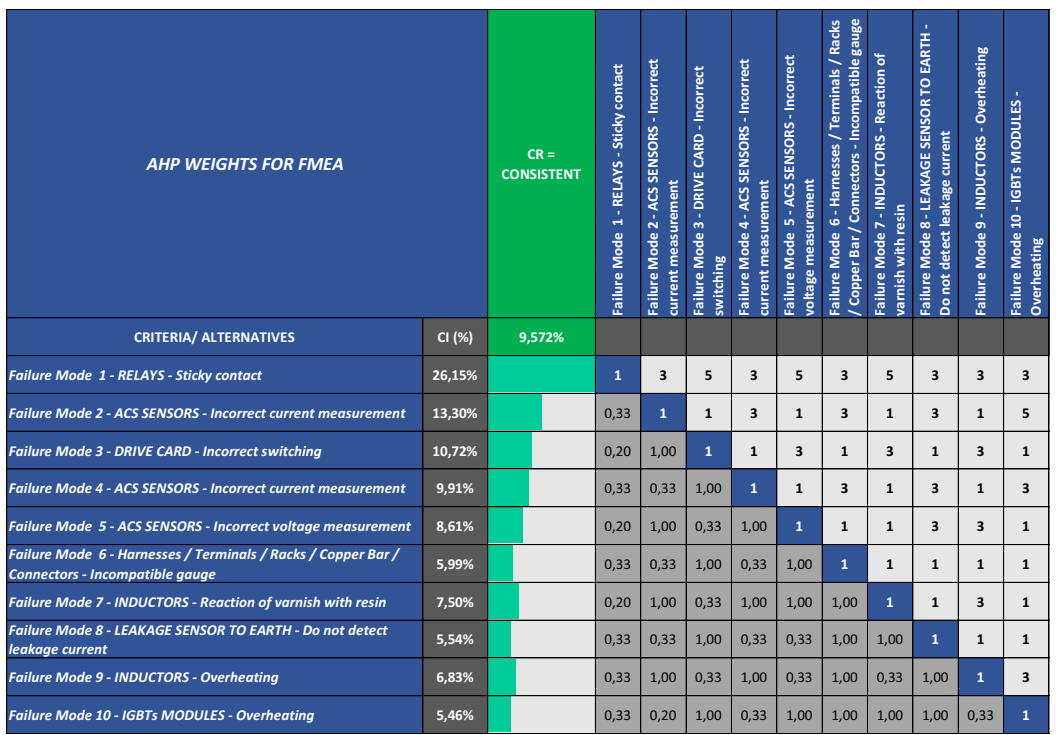

Figure 4. AHP Pairwise Comparison.

The criteria went through a pairwise comparison, made with the company's evaluators, resulting in the judgemental matrix (Figure 4). The spreadsheet tool developed was used to apply the AHP method, calculating the consistency of the pairwise comparison. As depicted, in the view of the evaluators, the sticky contact is the failure mode which they are more prepared to solve in terms of R\&D know-how. In the end, the application of the AHP returned the weight importance for each criterion, as depicted in Figure 5 .

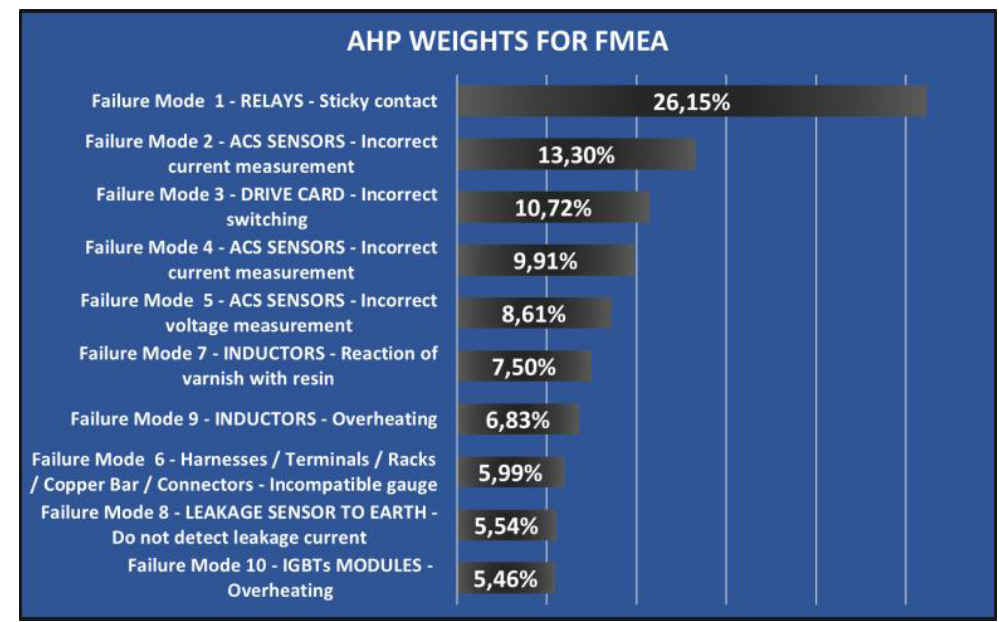

Figure 5. AHP weights on Failure Modes. 
The weighting scale from AHP served as the basis for the application of the next step of the approach, the TOPSIS method (Detail 3 of Figure 3). The TOPSIS was organised regarding the Identified Failure, Priority Criteria (Severity, Detection, Occurrence), the weight of the criteria (from the AHP results), Minimum and Maximum Value of the scale (1 and 10, based on original FMEA), and Number of Evaluators (in this case, three). This step of the approach, in summary, adapts the FMEA calculation to the TOPSIS notation.

\begin{tabular}{|c|c|c|c|c|c|c|}
\hline \multicolumn{7}{|c|}{ TOPSIS - MCDM Tool } \\
\hline & IDENTIFIED FAILURES & $\begin{array}{c}\text { FMEA } \\
\text { Priority Criteria }\end{array}$ & $\begin{array}{c}\text { Weight } \\
\text { of Criteria }\end{array}$ & $\begin{array}{l}\text { Qualitative Scale - } \\
\text { Minimun Value }\end{array}$ & $\begin{array}{l}\text { Qualitative Scale - } \\
\text { Maximun Value }\end{array}$ & $\begin{array}{l}\text { Number of } \\
\text { Evaluators }\end{array}$ \\
\hline 1 & Failure Mode 1 - RELAYS - Sticky contact & SEVERITY (S) & $26,15 \%$ & 1 & 10 & Evaluator 1 \\
\hline 2 & $\begin{array}{l}\text { Failure Mode } 2 \text { - ACS SENSORS - Incorrect } \\
\text { current measurement }\end{array}$ & DETECTION (D) & $13,30 \%$ & 1 & 10 & Evaluator 2 \\
\hline 3 & $\begin{array}{l}\text { Failure Mode } 3 \text { - DRIVE CARD - Incorrect } \\
\text { switching }\end{array}$ & OCCURENCE (O & $10,72 \%$ & 1 & 10 & Evaluator 3 \\
\hline 4 & $\begin{array}{l}\text { Failure Mode } 4 \text { - ACS SENSORS - Incorrect } \\
\text { current measurement }\end{array}$ & & $9,91 \%$ & 1 & 10 & \\
\hline 5 & $\begin{array}{l}\text { Failure Mode } 5 \text { - ACS SENSORS - Incorrect } \\
\text { voltage measurement }\end{array}$ & & $8,61 \%$ & 1 & 10 & \\
\hline 6 & $\begin{array}{l}\text { Failure Mode } 6 \text { - Harnesses / Terminals / } \\
\text { Racks / Copper Bar / Connectors - } \\
\text { Incompatible gauge }\end{array}$ & & $5,99 \%$ & 1 & 10 & \\
\hline 7 & $\begin{array}{l}\text { Failure Mode } 7 \text { - INDUCTORS - Reaction of } \\
\text { varnish with resin }\end{array}$ & & $7,50 \%$ & 1 & 10 & \\
\hline 8 & $\begin{array}{l}\text { Failure Mode } 8 \text { - LEAKAGE SENSOR TO EARTH - } \\
\text { Do not detect leakage current }\end{array}$ & & $5,54 \%$ & 1 & 10 & \\
\hline 9 & Failure Mode 9 - INDUCTORS - Overheating & & $6,83 \%$ & 1 & 10 & \\
\hline 10 & $\begin{array}{l}\text { Failure Mode } 10 \text { - IGBTs MODULES - } \\
\text { Overheating }\end{array}$ & & $5,46 \%$ & 1 & 10 & \\
\hline
\end{tabular}

Figure 6. TOPSIS - Input data for the tool developed.

Data from the product's FMEA, referring to the priority criteria of each identified failure (Severity (S), Detection (D), Occurrence (O)) and Risk Priority Value (RPN) were inserted into the spreadsheet tool, followed by the evaluation of each member of the evaluators separately, per failure mode and based on the available FMEA, as depicted in Figure 7.

\begin{tabular}{|c|c|c|c|}
\hline \multirow{2}{*}{$\begin{array}{l}\text { Failure Mode } 1 \text { - RELAYS - Sticky } \\
\text { contact }\end{array}$} & \multicolumn{3}{|l|}{ EVALUATORS } \\
\hline & Evaluator 1 & Evaluator 2 & Evaluator 3 \\
\hline SEVERITY (S) & 10 & 9 & 8 \\
\hline DETECTION (D) & 5 & 5 & 5 \\
\hline OCCURENCE (O) & 4 & 4 & 4 \\
\hline RPN & 200 & 180 & 160 \\
\hline \multirow{2}{*}{$\begin{array}{l}\text { Failure Mode } 2 \text { - ACS SENSORS - } \\
\text { Incorrect current measurement }\end{array}$} & \multicolumn{3}{|l|}{ EVALUATORS } \\
\hline & Evaluator 1 & Evaluator 2 & Evaluator 3 \\
\hline SEVERTYY (S) & 7 & 8 & 9 \\
\hline DETECTION (D) & 6 & 6 & 6 \\
\hline OCCURENCE (O) & 4 & 4 & 4 \\
\hline RPN & 168 & 192 & 216 \\
\hline \multirow{2}{*}{$\begin{array}{l}\text { Fa ilure Mode 3- DRIVE CARD - } \\
\text { Incorrect switching }\end{array}$} & \multicolumn{3}{|l|}{ EVALUATORS } \\
\hline & Evaluator 1 & Evaluator 2 & Evaluator 3 \\
\hline SEVERTY (S) & 7 & 5 & 6 \\
\hline DETECTION (D) & 5 & 5 & 5 \\
\hline OCCURENCE (0) & 3 & 3 & 3 \\
\hline RPN & 105 & 75 & 90 \\
\hline \multirow{2}{*}{$\begin{array}{l}\text { Failure Mode } 4 \text { - ACS SENSORS - } \\
\text { Incorrect current measurement }\end{array}$} & \multicolumn{3}{|l|}{ EVALUATORS } \\
\hline & Evaluator 1 & \begin{tabular}{|l|} 
Evaluator 2 \\
\end{tabular} & Evaluator 3 \\
\hline SEVERTY (S) & 7 & 7 & 8 \\
\hline DETECTION (D) & 6 & 6 & 6 \\
\hline OCCURENCE (O) & 2 & 2 & 2 \\
\hline RPN & 84 & 84 & 96 \\
\hline \multirow{2}{*}{$\begin{array}{l}\text { Failure Mode } 5 \text {-ACS SENSORS - } \\
\text { Incorrect voltage measurement }\end{array}$} & \multicolumn{3}{|l|}{ EVALUATORS } \\
\hline & Evaluator 1 & Evaluator 2 & Evaluator 3 \\
\hline SEVERTYY (S) & 10 & 9 & 8 \\
\hline DETECTION (D) & 4 & 4 & 4 \\
\hline OCCURENCE (O) & 2 & 2 & 2 \\
\hline RPN & 80 & 72 & 64 \\
\hline
\end{tabular}

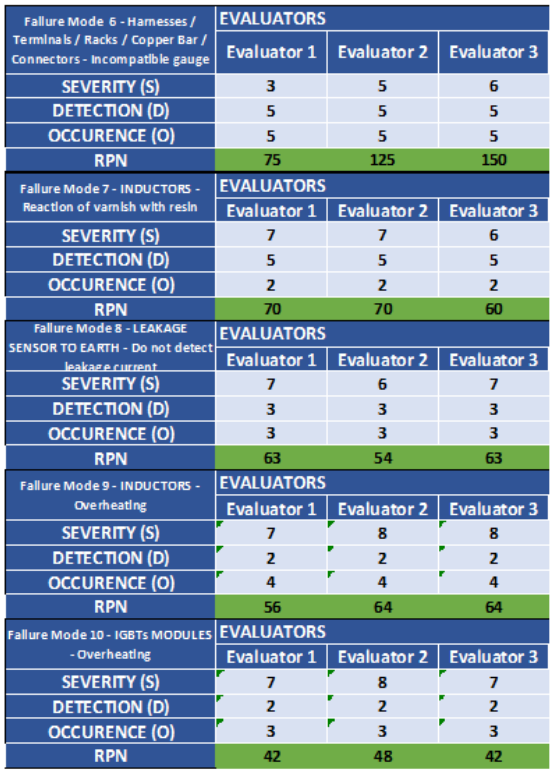

Figure 7. TOPSIS - FMEA data from the three evaluators for each identified failure. 
Furthermore, the general classification of priorities was obtained associating FMEA with the MCDM approach, considering the combinations of all three evaluators' analysis. The objective was to identify the impact on classification for the evaluators, both individually and in groups, and thus be able to infer if the MCDM approach for FMEA presents a significant difference in results on the final order of prioritisation with and without MCDM. The results are shown in Figure 8.

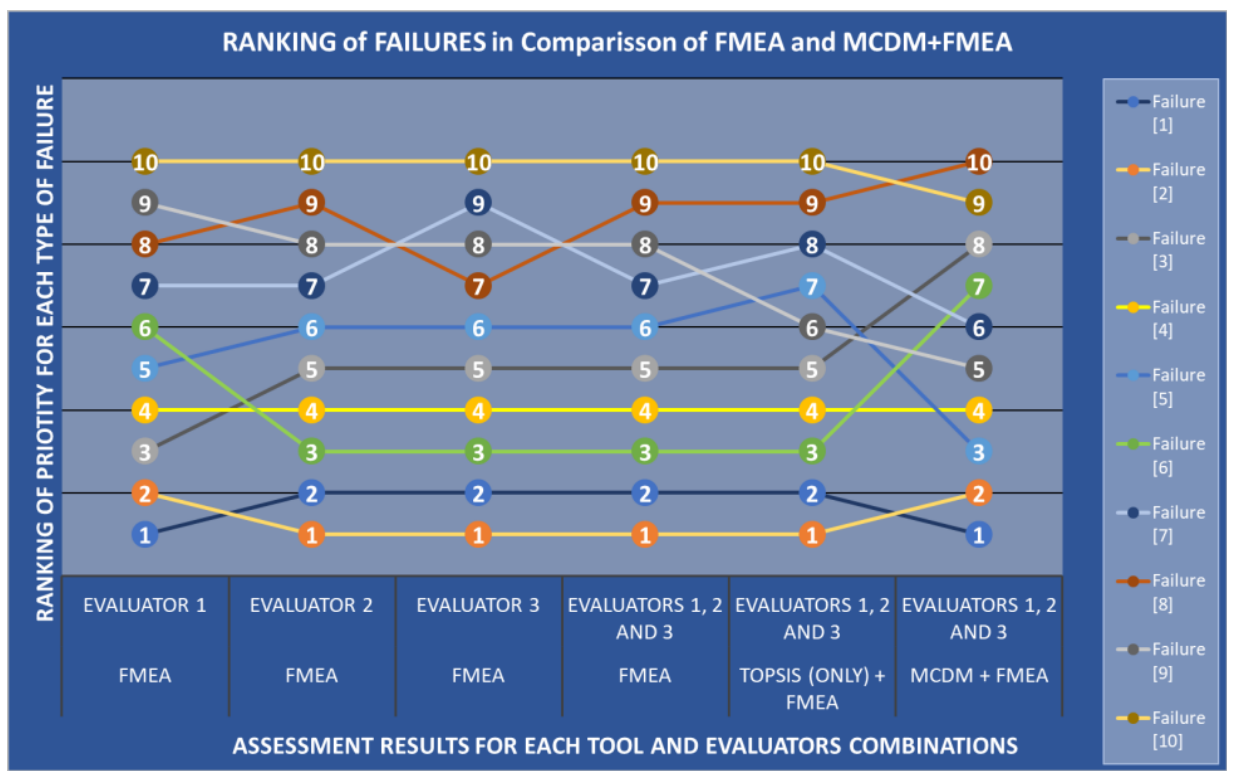

Figure 8. Comparison of Methods.

The ranking differences in Figures 8 represent the divergence regarding the evaluators' considerations when applying FMEA and their considerations with the application of the MCDM approach. When considering the final ranking provided by the application of the MCDM techniques, there are significant differences regarding the results from the evaluators applying only FMEA. The application of both MCDM techniques resulted in a significant change in the final results. To improve comparison TOPSIS alone with the FMEA evaluation was represented as well, providing changes on the final results of FMEA as well.

\section{Results and Discussion}

Through the application of AHP and TOPSIS in association with FMEA, it was possible to note a difference between evaluators from different departments and the overall order of relevance of failure modes. In this sense, AHP and TOPSIS could work as a mediator to improve the decision-making, avoiding the necessity of discussion and consensus between evaluators (which can be time-consuming) in the final results of FMEA, providing an improved approach that can work as a basis for new FMEA applications.

In the literature review of the conceptual background, other approaches associating FMEA with MCDM methods were found, but with some differences regarding scales, application field and mostly the different methodologies to provide weighing scales. In Bian ${ }^{[6]}$, for instance, authors changed the weight system by including D-Numbers, to 
reduce uncertainty when weighting FMEA for application of the TOPSIS. This research opted by using the regular scale and attributing weights based on AHP results, as the focus of the research resides in creating an approach to FMEA based on MCDM techniques.

The AHP application made easier to establish the importance for each of the Failure Modes in the vision of the company's specialists. In this sense, this customizable scale for different scenarios may improve overall decisions on criteria and the results of applications with other MCDM techniques. The AHP weighting based on the company's preparedness to solve failure modes provided a major impact on the results, overall.

The application of the TOPSIS method in the FMEA process of the company ended up by improving the process in terms of agility, by reducing the discussion on weighting, scales and the consensus of final values. As a result of this process, a change in the process was suggested by evaluators, by elaborating forms for each of them and processing the results through the TOPSIS tool, ending up on a more robust FMEA for the company's R\&D team.

As for the final results of the MCDM approach for FMEA, it is possible to see that the techniques' implementation has a significant impact on the final results of the FMEA. This occurs due to an improved definition of the criteria relevance concerning each other, which improve the prioritisation of action plans. The results show that differences between evaluators are more easily coped when the MCDM techniques are used, as their algorithm can cope with different evaluators. It is possible to infer that the application of the MCDM techniques provides a more precise prioritisation on FMEA, as subjectiveness and possible bias of evaluator are reduced.

\section{Conclusion}

The proposed multi-criteria approach was able to improve and better represent divergent visions on FMEA, reducing heterogeneity in interpretation, subjectiveness, and bias in the evaluation process, while creating a new standard for the company's R\&D.

The approach provided an improved FMEA experience for product developers, and have the potential to become a day-to-day part of other operations while improving standardisation and the documentation of process indirectly.

Further works are related to the development of professional tools for MCDM and FMEA, as well as other Product Development Tools and MCDM techniques. Furthermore, it is suggested that an integrated platform of MCDM and Product Development Tools would improve the Product Development Process.

\section{Acknowledgement}

The authors would like to acknowledge the company where the study was conducted and the Industrial and Systems Engineering Graduate Program (PPGEPS) of the Pontifical Catholic University of Paraná (PUCPR) for the structure and funding.

\section{References}

[1] Y. Liao, F. Deschamps, E. de F. R. Loures, and L. F. P. Ramos, Past, present and future of Industry 4.0 - 
a systematic literature review and research agenda proposal," Int. J. Prod. Res. , 2017, Vol. 55, No. 12, pp. 3609-3629.

[2] M. Nagy, M. Vargas-Vera. Towards an automatic semantic data integration: Multi-agent framework approach, Semantic Web, 2010, Jan 1:107-34.

[3] M. van Sinderen, B. Sapkota, Architectures, Concepts and Technologies for Service Oriented Computing: Proceedings of the 2nd International Workshop on Architectures, Concepts and Technologies for Service Oriented Computing-ACT4SOC 2008, https://research.utwente.nl/files/5123925/ACT4SOC_2010.pdf, accessed July, 12020.

[4] A.F.C.S.M. Leite, A.L. Szejka, O. Canciglieri Junior, R.C. Annunziato, A Discussion on Current Issues for Semantic Interoperability in an Integrated Product Development Process. In: Chiabert P., Bouras A., Noël F., Ríos J. (eds) Product Lifecycle Management to Support Industry 4.0. PLM 2018. IFIP Advances in Information and Communication Technology, vol 540. Springer, Cham, 2018, pp. 117-125.

[5] J.C. Battirola Filho, F. Piechnicki, E.R. Loures, E.A.P. Santos, Process-aware FMEA framework for failure analysis in maintenance. Journal Of Manufacturing Technology Management, 2017, Vol. 28, pp. 822-848.

[6] T. Bian, H. Zheng, L. Yin and Y. Deng, Failure mode and effects analysis based on D numbers and TOPSIS, Quality and Reliability Engineering International, 2018, Vol. 34(4), pp. 501-515.

[7] D. E. Gray. Doing Research in The Real World. 3 ed., SAGE Pub, London, 2012.

[8] F. Heindl, Adreas; Werbik, Alexander; Winter, Johannes; Mayer, Bernd; Zarpellom, Bruno; Remann et al., "Possibilidades de colaboração com a cooperação para o desenvolvimento e a economia alemã na área de tecnologia / transferência de know-how para o Brasil," Acatech, 2016.

[9] E. Pessl, S.R. Sorko, B.L. Dudel Mayer, Roadmap Industry 4.0 - Implementation Guideline for Enterprises, Int. J. Sci. Technol. Soc., 2017, Vol. 5, No. 6, pp. 193-202.

[10] J. Singh, An Analysis of Critical Success Factors for Industry 4.0: An Application of Analytical Hierarchy Process, Ind. Eng. J., 2018, Vol. 11, No. 9, pp. 1-15.

[11] U. Fayyad, G. Piatetsky-Shapiro, P. Smyth, From Data Mining to Knowledge Discovery in Databases. American Association for Artificial Intelligence, 1996.

[12] H. Jiawei, K. Micheline, P. Jian, Data Mining Concepts and Techniques. 3rd edition. Morgan Kaufmann, Waltham, 2012.

[13] H. Jamshed, M. S. A. Khan, M. Khurram, S. Inayatullah, and S. Athar, Data Preprocessing: A preliminary step for web data mining, 3C Tecnol. innovación Apl. a la pyme, 2019, May, pp. 206-221.

[14] M. Hermann, T. Pentek, and B. Otto, Design principles for Industrie 4.0 scenarios, Proc. Annu. Hawaii Int. Conf. Syst. Sci. , 2016, Vol. 2016-March, pp. 3928-3937.

[15] M. B. Canciglieri, A. F. C. S. M. Leite, A. L. Szejka and O. Canciglieri Júnior. An approach for dental prosthesis design and manufacturing through rapid manufacturing technologies, International Journal of Computer Integrated Manufacturing, 2019, 32:9, pp. 832-847.

[16] M. Hambleton, Applying root cause analysis and failure mode and effect analysis to our compliance programs, Journal of Health Care Compliance, No. 2, April. 2005, pp. 303-311.

[17] K. D. Sharma and S. Srivastava, Failure Mode and Effect Analysis (FMEA) Implementation: A Literature Review, Copyr. J. Adv. Res. Aeronaut. Sp. Sci. J Adv Res Aero SpaceSci, 2018, Vol. 5, no. 2, pp. 24548669.

[18] T. Hendrickx, B. Cule, P. Meysman, S. Naulaerts, K. Laukens, and B. Goethals, Mining association rules in graphs based on frequent cohesive itemsets, Lect. Notes Comput. Sci. (including Subser. Lect. Notes Artif. Intell. Lect. Notes Bioinformatics), 2015, Vol. 9078, no. 3, pp. 637-648.

[19] S.H. Zyoud and D. Fuchs-Hanusch, A bibliometric-based survey on AHP and TOPSIS techniques. Expert systems with applications, 2017, 78, pp.158-168

[20] J.J. Thomas and K.A. Cook, Illuminating the Path: The Research and Development Agenda for Visual Analytics. IEEE CS Press, Los Alamitos, 2005.

[21] T. L. Saaty, Theory and applications of the analytic network process: decision making with benefits, opportunities, costs, and risks. RWS publications, Pittsburgh, 2005.

[22] H. Veisi, H. Liaghati, and A. Alipour, Developing an ethics-based approach to indicators of sustainable agriculture using analytic hierarchy process (AHP). Ecological Indicators, 2016, 60, pp. 644-654. 